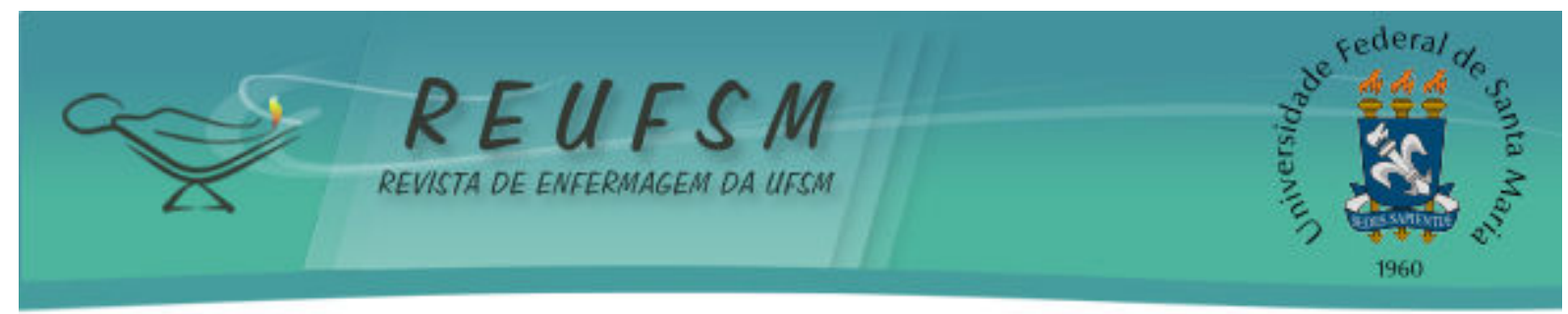

ARTIGO ORIGINAL

\title{
GÊNERO E SEXUALIDADE: INFLUÊNCIAS NA PREVENÇÃO DAS DSTS/AIDS E AS CONTRIBUIÇÕES PARA A ENFERMAGEM
}

\section{GENDER AND SEXUALITY: INFLUENCES IN THE PREVENTION OF STDS/AIDS AND THE CONTRIBUTIONS FOR NURSING}

\section{GÉNERO Y SEXUALIDAD: INFLUENCIAS EN PREVENCIÓN DE ETS / SIDA Y CONTRIBUCIONES PARA LA ENFERMERÍA}

\author{
Graciela Dutra Sehnem ${ }^{1}$ \\ Joice Moreira Schmalfuss ${ }^{2}$ \\ Priscila de Oliveira Bolzan Bonadiman ${ }^{3}$ \\ Fabiani Weiss Pereira ${ }^{4}$ \\ Jussara Mendes Lipinski ${ }^{5}$ \\ Lisiani Bogorni ${ }^{6}$
}

\section{Doi: $10.5902 / 2179769212408$}

RESUMO: Objetivo: conhecer como a construção de gênero e de sexualidade influenciam na prevenção das DSTs/AIDS. Método: pesquisa de campo, descritiva, exploratória, de abordagem qualitativa. Doze mulheres atendidas em uma Unidade Básica de Saúde de Uruguaiana/RS foram entrevistadas entre setembro e outubro de 2012. Os dados foram submetidos à análise de conteúdo do tipo temática. Resultados: a categoria "A construção do ser mulher e suas repercussões na prevenção das DSTs/AIDS" sinalizou a necessidade de promover a equidade de gênero, considerando o planejamento de ações que visem diminuir as vulnerabilidades em saúde da mulher. A categoria "Sexualidade feminina: repercussões na prevenção das DSTs/AIDS" mostrou a sexualidade relacionada não somente à prática sexual puramente biológica, mas também entendida como noção de corpo, de relacionamentos, sentimentos e respeito. Considerações finais: a Enfermagem tem papel fundamental na educação em saúde e na contribuição para o processo de empoderamento das mulheres em relação a sua saúde.

Descritores: Saúde da mulher; Sexualidade; Identidade de gênero; Enfermagem.

ABSTRAC: Objective: to raise awareness about how the constructions of gender and sexuality influence the prevention of the STDs/AIDS. Method: exploratory, descriptive field research with a qualitative approach. Twelve women assisted at a Basic Health Unit in Uruguaiana/RS were interviewed between September and October 2012. The data was submitted to thematic content analysis. Results: the category "The construction of being

\footnotetext{
${ }^{1}$ Enfermeira. Doutora em Enfermagem. Docente do Curso de Enfermagem da Universidade Federal do Pampa-Campus Uruguaiana/RS/Brasil. E-mail: graci_dutra@yahoo.com.br

2 Enfermeira. Mestre em Enfermagem. Docente do Curso de Enfermagem da Universidade Federal da Fronteira Sul-Campus Chapecó/SC/Brasil. E-mail: joicemschmalfuss@gmail

${ }^{3}$ Enfermeira. Mestre em Saúde Coletiva. Enfermeira Assistente do Hospital Universitário de Santa Maria-Santa Maria/RS/Brasil. E-mail: priscilabonadiman@gmail.com

${ }^{4}$ Enfermeira. Mestranda pelo Programa de Pós-Graduação em Enfermagem de Rio Grande (PPGEnf/FURG)-Rio Grande/RS/Brasil. E-mail: enffabiweiss@hotmail.com

${ }^{5}$ Enfermeira. Doutora em Enfermagem. Docente do Curso de Enfermagem da Universidade Federal do Pampa-Campus Uruguaiana/RS/Brasil. E-mail: jussaralipinski@gmail.com

${ }^{6}$ Enfermeira. Graduada pela Universidade Federal do Pampa-Campus Uruguaiana/RS/Brasil. Email: lisibog16@hotmail.com
} 


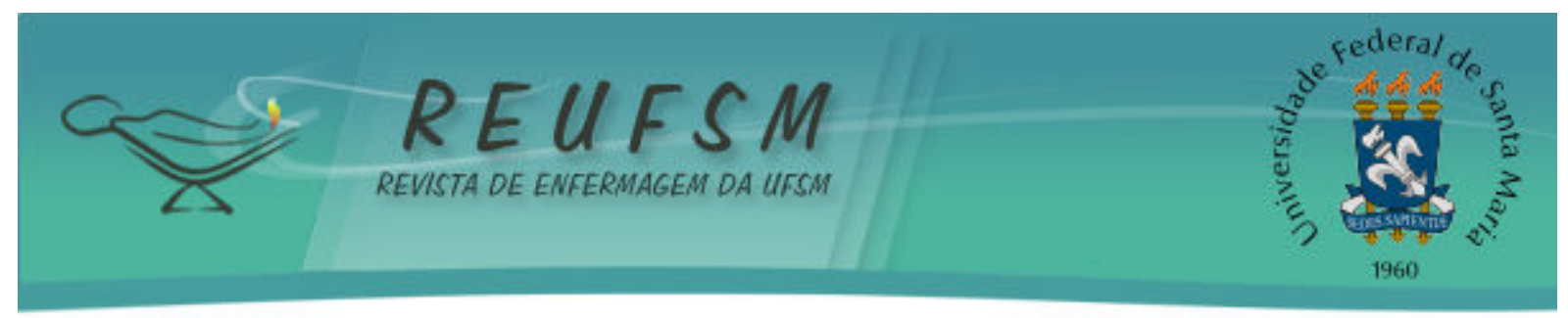

a woman and its repercussions in the prevention of STDS/AIDS" showed the necessity to promote gender equality, considering the planning of actions which aim to reduce the vulnerabilities in women's health. The category “Female sexuality: repercussions in the prevention of STDS/AIDS" showed the sexuality not only as related to purely biological sexual activity, but also understood as an idea of body, relationships, feelings and respect. Final considerations: Nursing plays a fundamental role in health education and in the contribution to the process of women empowerment in relation to their health.

Descriptors: Women's health; Sexuality; Gender identity; Nursing.

RESUMEN: Objetivo: conocer la influencia de la construcción de género y de sexualidad en la prevención de ETS/SIDA. Método: estudio de campo, descriptivo, exploratorio, cualitativo. Doce mujeres atendidas en una Unidad Básica de Salud de Uruguaiana (RS, Brasil) fueron entrevistadas entre septiembre/octubre de 2012. Datos analizados según análisis de contenido temático. Resultados: la categoría "La construcción del ser mujer y sus repercusiones en la prevención de las ETSs/SIDA" señaló la necesidad de promover equidad de género, considerando el planeamiento de acciones para disminuir las vulnerabilidades en salud de la mujer. La categoría "Sexualidad femenina: repercusiones en la prevención de las ETSS/SIDA" mostró la sexualidad relacionada no solamente a prácticas sexuales puramente biológicas, sino también entendida como noción de cuerpo, de relaciones, sentimientos y respeto. Consideraciones finales: la Enfermería tiene un papel fundamental en educación en salud y la contribución para el proceso de empoderamiento de mujeres en relación a su salud.

Descriptores: Salud de la mujer; Sexualidad; Identidad de género; Enfermería.

\section{INTRODUÇÃO}

As políticas de atenção à saúde da mulher, formuladas nacionalmente por meio de amplas e complexas discussões, trouxeram contribuições imprescindíveis para o processo de transformação do paradigma da saúde da mulher no Brasil. Porém, apesar dos avanços, esse processo ainda acompanha a transformação da sociedade e, por isso, é inexaurivel. ${ }^{1}$

Nesse contexto, salienta-se que, dentre os objetivos específicos da Política Nacional de Atenção Integral à Saúde da Mulher, encontra-se promover a prevenção e o controle das Doenças Sexualmente Transmissíveis (DSTs) e da infecção pelo vírus da imunodeficiência humana (HIV) na população feminina ${ }^{2}$, tendo em vista que as DSTs acometem a população a nível mundial e constituem um expressivo problema de saúde pública. ${ }^{3}$ Além disso, no que se refere às DSTs em geral, existe a preocupação com a invisibilidade das que não são de notificação compulsória, bem como das tratadas, muitas vezes, com automedicação, o que dificulta a dimensão real do problema, bem como a elaboração de estratégias para o seu controle. ${ }^{3}$

No início da década de 1990, o crescimento de casos de AIDS entre as mulheres e da transmissão do HIV de mãe para filho alertou a sociedade para a questão. Nesse sentido, a temática da feminização da epidemia surge como ponto de discussão e alerta aos profissionais da saúde, pois de acordo com as estimativas do Programa Conjunto das Nações Unidas sobre HIV/AIDS (UNAIDS), 50\% das pessoas infectadas no mundo são mulheres. ${ }^{4}$ No Brasil, em 2012, foram notificados 8.622 casos de AIDS em mulheres, sendo destes $96,6 \%$ decorrentes de exposição sexual, entre casais heterossexuais. ${ }^{5}$

Em vista disso, é importante refletir o quanto este processo pode ser influenciado por desigualdades de gênero, que repercutem em atitudes de prevenção, como o uso do preservativo durante as relações sexuais. Compreende-se, então, gênero enquanto categoria de análise que considera a construção histórica e social das relações entre o 


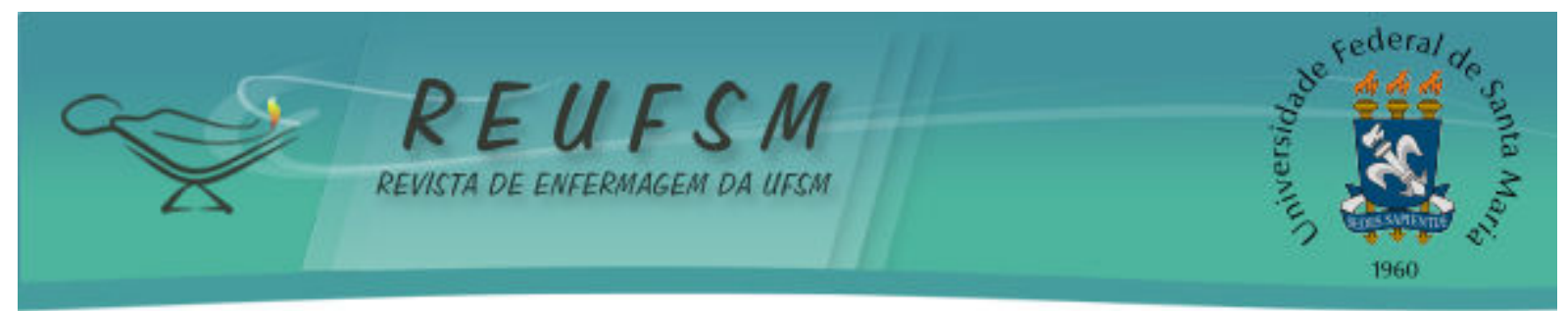

masculino e o feminino, delimitando modelos de comportamento a partir do nascer homem ou mulher. ${ }^{6}$

Esse contexto sugere a necessidade de reflexão sobre as questões de gênero como determinantes de saúde, uma vez que o Ministério da Saúde já reconhece gênero enquanto categoria para construção das políticas de saúde da mulher. ${ }^{2}$ Assim, acredita-se que as desigualdades perpetuadas a partir das construções de gênero podem inferir negativamente nas práticas de cuidado e saúde femininas, pois constituem-se crenças que acabam por definir atitudes e comportamentos. ${ }^{2}$

Dessa forma, o pensamento tradicional impõe o desejo sexual e a vivência plena da sexualidade enquanto característica essencial do homem, introjetando às mulheres o sexo para a reprodução e manutenção da família e, assim, constrói-se uma cultura em que há a naturalização da passividade. ${ }^{\grave{7}}$ Têm-se os reflexos dessa construção representados na submissão feminina no momento da negociação do uso do preservativo, por exemplo, deixando a decisão a cargo do homem, num exercício de poder intrínseco às relações de gênero. ${ }^{8}$

A vulnerabilidade feminina também pode ser influenciada por questões de desinformação, já que, muitas vezes, há preocupação apenas com a prevenção de gravidez indesejada com a utilização de contraceptivos orais, relegando o uso do preservativo sem associá-lo à prevenção, tanto de uma gravidez indesejada, quanto de DSTs/AIDS. Indicadores de conhecimentos, atitudes e práticas da população brasileira, levantados via inquérito domiciliar, mostram que, no geral, os homens possuem maior conhecimento acerca das formas de transmissão do HIV do que as mulheres, bem como, sobre o uso do preservativo como método preventivo. ${ }^{9}$

Nesse sentido, é fundamental que o enfermeiro incorpore em sua rotina a preocupação em identificar os pacientes em situação de maior vulnerabilidade ${ }^{3}$, garantindo-lhes o acesso à informação e um atendimento humanizado, já que a confirmação de uma DST acarreta diversas mudanças, tanto biológicas quanto psicológicas. No caso das mulheres, faz-se importante que o enfermeiro perceba seu papel de facilitador entre o público feminino e o conhecimento em saúde, de maneira a levar a informação e o diálogo a locais nos quais se perpetuem desigualdades de gênero.

Dessa forma, o problema de pesquisa norteador da investigação é embasado no seguinte questionamento: como a construção de gênero e sexualidade influenciam na prevenção das DSTs/AIDS de mulheres atendidas em uma Unidade Básica de Saúde (UBS) do município de Uruguaiana? Para responder esta questão este estudo objetivou conhecer como a construção de gênero e de sexualidade influenciam na prevenção das DSTs/AIDS de mulheres atendidas em uma UBS do município de Uruguaiana.

\section{MÉTODO}

Trata-se de um estudo de campo, descritivo, exploratório e com abordagem qualitativa, realizado em uma UBS do município de Uruguaiana/RS, na qual, semanalmente, são atendidas mulheres nas diversas fases de sua vida. O cenário desse estudo justifica-se pelo fato de que nessa unidade os atendimentos à saúde da mulher são realizados pela Enfermagem, fato que facilitou o acompanhamento das mulheres, a identificação do cenário e, consequentemente, a coleta dos dados.

Os temas que versam sobre gênero, sexualidade, DSTs e HIV/AIDS são abordados pela única enfermeira da UBS e responsável pela assistência à saúde da mulher, durante as consultas de Enfermagem que são realizadas individualmente e direcionadas às demandas ginecológicas e obstétricas. 


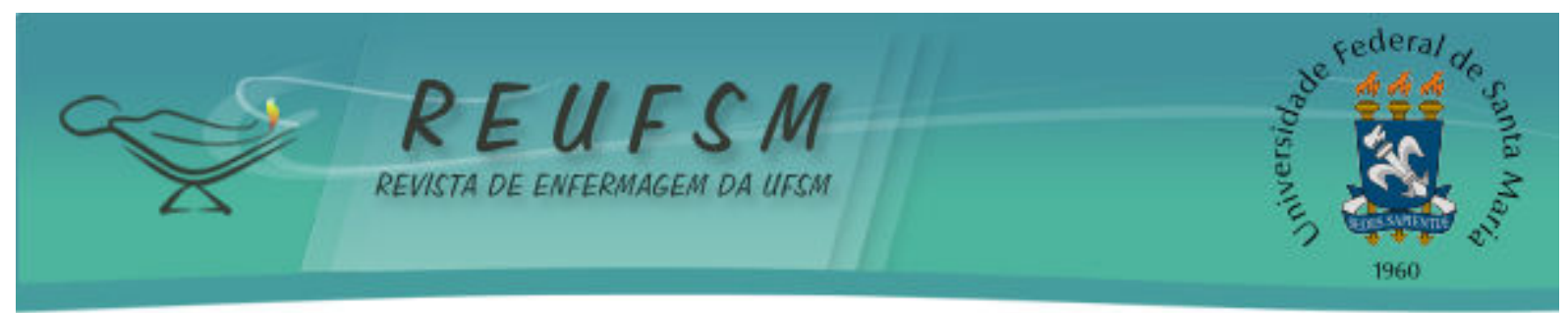

As mulheres participantes do estudo foram convidadas a participar do mesmo a partir de contatos realizados de forma verbal e aleatória antes ou após as consultas de Enfermagem, na sala de espera e em outros momentos que buscaram o atendimento na referida Unidade. Após o esclarecimento acerca da finalidade da pesquisa e da aprovação de cada sujeito foram agendadas as entrevistas, conforme a disponibilidade de cada mulher, cabendo à mesma a definição do local e o horário da entrevista. 0 dimensionamento da quantidade de sujeitos pesquisados na etapa de coleta de dados foi decidido conforme a repetição dos dados, sendo interrompida quando os mesmos passaram a ser repetitivos.

Foram critérios de inclusão da pesquisa: mulheres atendidas na UBS e moradoras em sua área de abrangência, com idade superior a 18 anos e com vida sexual ativa. A fim de preservar a identidade das participantes incluídas no estudo, as mesmas foram identificadas com a letra "E” para entrevista, seguidas pela numeração de um a 12.

A coleta de dados foi realizada entre setembro e outubro de 2012 , em variados dias da semana, na própria UBS, em sala que garantiu a privacidade da entrevistada, bem como da entrevista, brevemente após o convite feito pela pesquisadora responsável pela coleta de dados.

Como técnica de coleta de dados foi empregada a entrevista semiestruturada que contou com a utilização de um roteiro previamente definido, com questões guias, o qual serviu como fio condutor para que a entrevista contemplasse o objetivo do estudo. Fizeram parte da entrevista perguntas que abordaram questões sobre o ser mulher; a sexualidade e sua vivência; conhecimento e prevenção das DSTs; informações recebidas por profissionais da saúde sobre métodos preventivos e DSTs e formas/momentos de recebimento destas informações (em grupos, consultas, visitas domiciliares, entre outros). As entrevistas tiveram uma duração média de 20 minutos e foram registradas em um gravador digital do tipo MP3 Player e transcritas pela pesquisadora.

Como técnica de análise dos dados, foi utilizada a análise temática, composta pelas seguintes fases: pré-análise, exploração do material e tratamento dos resultados obtidos e interpretação. ${ }^{10}$

$\mathrm{Na}$ fase de pré-análise foi realizada uma leitura flutuante do conjunto das informações coletadas, posteriormente se deu a constituição do corpus considerando normas como a exaustividade, representatividade, homogeneidade e pertinência dos dados e, por fim, se formulou e reformulou as hipóteses e objetivos, retomando a etapa exploratória. Assim, nesta fase foram determinadas a unidade de registro, a unidade de contexto, os recortes, a forma de categorização, a modalidade de codificação e os conceitos teóricos que nortearam a análise. ${ }^{10}$

A segunda fase foi delineada por uma intervenção classificatória que buscou alcançar o núcleo de compreensão do texto. Os dados foram organizados a partir de categorias, reduzindo o escrito a expressões e palavras significativas. Finalmente, na última fase, tratamento dos resultados obtidos e interpretação, as informações levantadas foram interpretadas. ${ }^{10}$

Esta pesquisa seguiu os preceitos éticos da Resolução $n^{\circ}$ 196/96, vigente na época de realização do estudo, do Conselho Nacional de Saúde que rege pesquisas envolvendo seres humanos. ${ }^{11} \mathrm{O}$ estudo obteve aprovação do Comitê de Ética e Pesquisa da Universidade Federal do Pampa, sob o número 58422, em agosto do ano de 2012. Todos os sujeitos do estudo concordaram em participar da pesquisa mediante a assinatura do Termo de Consentimento Livre e Esclarecido. 


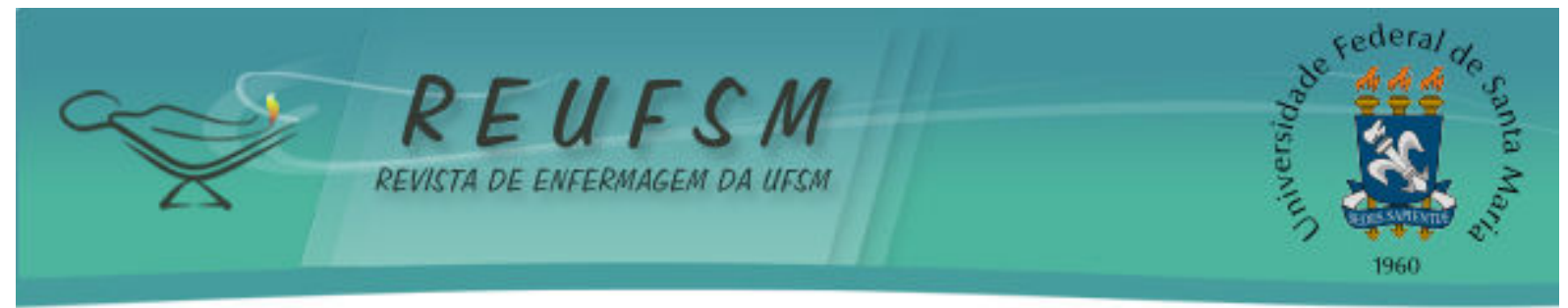

\section{RESULTADOS E DISCUSSÃO}

As 12 mulheres participantes do estudo tinham idade entre 19 e 54 anos, vida sexual ativa e, em sua maioria, companheiros fixos. Quanto à escolaridade, a maior parte das entrevistadas estudou até o ensino fundamental. Todas mulheres residiam com familiares.

A partir da análise temática, emergiram das falas dos sujeitos as seguintes categorias: "A construção do ser mulher e suas repercussões na prevenção das DSTs/AIDS" e "Sexualidade feminina: repercussões na prevenção das DSTs/AIDS".

\section{A construção do ser mulher e suas repercussões na prevenção das DSTs/AIDS}

A construção do ser mulher é um processo contínuo e infindável, que se inicia ao nascimento com o sexo biológico e, posteriormente, passa por influências sociais e culturais, as relações de gênero. Em virtude disso, entende-se que o sexo naturalmente determinado é, gradativamente, influenciado por outras questões, as quais podem determinar modos de ser e agir.

Assim, a constituição do ser mulher se faz superior à diferenciação biológica e pode implicar em termos de seguir modelos de feminilidade, os quais impõem comportamentos aceitáveis e esperáveis, a partir do nascer mulher. Nesta pesquisa, houve posicionamentos distintos a esse respeito. Alguns depoimentos expressaram a construção feminina relacionada à manutenção da casa e da família.

Ser mulher é maravilhoso, ter uma família, ter um bom esposo, ser feliz, trabalhar em casa, ir na igreja e fazer a função do dia a dia [...]. (E2)

[...] mulher é mãe, mulher menstrua, é dona de casa, tem várias funções. (E4)

Ser mulher é trabalhar dentro de casa. (E7)

Ser mulher é ser esposa, dona de casa, várias coisas ao mesmo tempo. (E9)

Nesse sentido, os achados corroboram com outro estudo, o qual encontrou o "ser mulher" relacionado a ser amorosa, responsável, esposa, mãe, reservada e delicada. Assim, reafirma-se a influência das relações sociais fundadas sobre as diferenças percebidas entre os gêneros, com a ideia de que a mulher já nasce com essas características. ${ }^{12}$

Neste contexto, as mulheres expressaram comportamentos denotando certa dependência de seus companheiros e passividade no que se refere ao cuidado com a própria saúde, expressando, por exemplo, que não utilizam o preservativo nas relações sexuais em nome da confiança e estabilidade do relacionamento conjugal. Nesses casos, a proteção contra DSTs/AIDS não acontece.

Meu esposo tem que se cuidar, porque se ele trai a gente, a gente tá correndo perigo. (E2)

Com meu marido não uso camisinha, eu confio nele. (E4) 


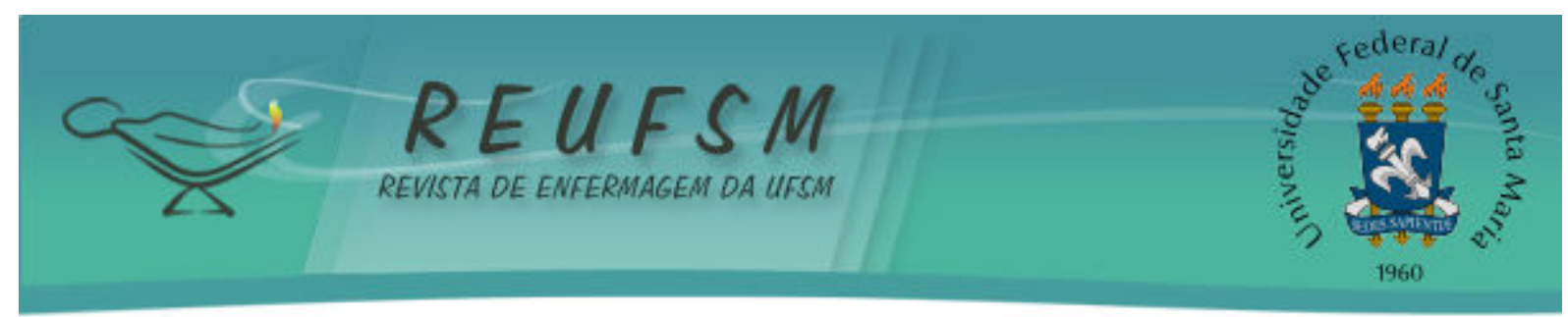

Eu não me protejo porque vivo com meu esposo, temos 35 anos de casados. (E9)

Sobre isso, outro estudo demonstrou que a maioria das mulheres entrevistadas tinha relações sexuais com parceiro fixo (namorado ou marido) sem uso de preservativo, havendo associação entre o uso de preservativo em todas as relações sexuais, porém quando o parceiro é casual. ${ }^{13}$ Da mesma forma, outra pesquisa identificou que a conjugalidade era justificativa para a não utilização do preservativo nas relações sexuais, pois havia a concepção opositora entre AIDS e amor/conjugalidade, atrelando ainda a doença a grupos específicos e sexo casual. ${ }^{14}$

Essa direção reflete uma visão feminina idealizada nas décadas de 60 e 80 , a qual designava à mulher um papel direcionado à criação dos filhos, ao serviço doméstico e à função reprodutora, subjugando-a, muitas vezes, como submissa ao cônjuge. Este fato pode acabar influenciando a conduta feminina perante a prevenção das DSTs e AIDS, no sentido de não fazê-la. ${ }^{3}$

Em contrapartida, no presente estudo, algumas mulheres relataram a não submissão e subjugação ao homem, observando-se a vivência de relações a partir da independência feminina, o que advém de uma concepção mais moderna da construção de gênero, na qual a submissão já não está mais tão presente e há uma menor submissão ao cônjuge. Assim, houveram relatos relacionados à independência em relação ao companheiro, tanto financeira, quanto relacionada ao autocuidado em saúde.

[...] para mim, ser mulher é ser alguém independente, não depender geralmente do marido, porque mulher é muito dependente de marido. Estou sempre dizendo, mulher não precisa de homem pra sobreviver, pra se sustentar, já é uma coisa cultural [...]. A gente tem que se cuidar, se tu não se cuidar, se não ter amor à vida, não tem remédio que cure. (E1)

[...] eu trabalho, porque se é pelo marido a gente fica só em casa, lavando roupa. Não, eu gosto de ter o meu dinheiro, não gosto de estar pedindo, me dá dinheiro para isso, para aquilo. [...] Eu acho que a pessoa tem que se cuidar muito, ver com quem anda. (E5)

Após décadas de submissão, as mulheres passaram a aprimorar seus conhecimentos, a investir na educação e a prosperar para uma vida social mais ativa, havendo maior investimento profissional, com direito a gozar de uma vida digna, sem censura e garantindo recursos próprios para a sua sobrevivência. Desse modo, a mulher passou a submeter-se cada vez menos ao sexo oposto. ${ }^{15}$

A visão das mulheres não mais ligadas única e exclusivamente às atividades domésticas e à educação dos filhos, passou a não mais submetê-las às imposições sociais antigas, as quais descreviam sua missão como de servidão, tanto à família quanto aos filhos. Esta conquista diminuiu a opressão tanto nas modalidades sexuais e econômicas, quanto nas intelectuais e emocionais. ${ }^{16}$ Acredita-se que esse posicionamento não submissivo proporciona expectativas positivas no que se refere a empoderar essas mulheres para comportamentos de autocuidado em saúde, tal como é a prevenção das DSTs/AIDS, muito embora nesse estudo não tenham sido produzidas falas que comprovassem tal afirmação.

Assim, permanece o desafio da promoção da equidade entre gêneros, já que a ideia de equidade implica na oferta de condições para a superação de desigualdades 


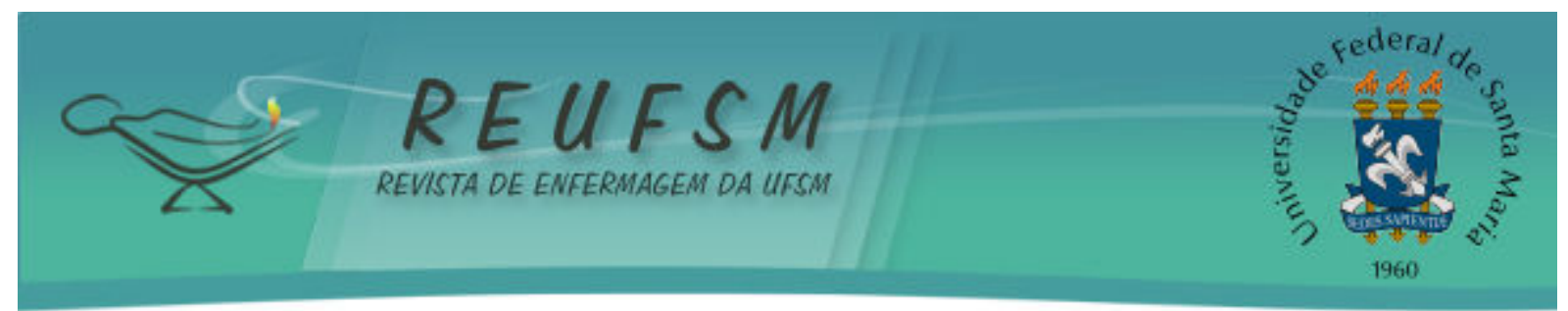

determinadas pelo contexto histórico e social de gênero. Logo, implica em um processo de reconhecimento das diferenças e, a partir disso, planejamento de ações para diminuição das vulnerabilidades em saúde da mulher.

A superação dessas desigualdades pressupõe, então, a implementação de ações que beneficiem as mulheres, considerando suas conquistas, proporcionando o acesso integral à saúde e o direito ao tratamento, como sujeitos sociais e cidadãs. ${ }^{15}$ Portanto, almeja-se reduzir as desigualdades, promover a saúde e prevenir doenças que estão diretamente relacionadas à vulnerabilidade da mulher ao HIV/AIDS. Diante disso, enfatizase a importância do investimento em ações estratégicas por parte dos profissionais de saúde, as quais incluem ampliar e qualificar atividades de assistência à saúde, bem como, proporcionar acolhimento e escuta a essas mulheres. ${ }^{2}$

\section{Sexualidade feminina: repercussões na prevenção das DSTs/AIDS}

As mulheres constroem suas percepções acerca da sexualidade conforme sua visão de mundo, que é determinada por influências sociais e culturais. Nesse estudo, algumas mulheres relacionam a sexualidade à prática sexual.

Eu, no meu ver, é sexo, porque como eu posso te dizer, eu já fui garota de programa, no nosso lado, sexo é aquela coisa de sair com um hoje, outro amanhã [...]. (E1)

Adoro! Entre quatro paredes vale tudo. (E5)

É sexo [...] sexo para mim não importa muito só, tem mulher que gosta, mas eu já não sou muito ligada, eu depois de quatro filhos já não tenho mais muita vontade. (E6)

Também emergiu outro olhar acerca da sexualidade que demonstra o amplo entendimento da temática, considerando que ela não se detém apenas às experiências sexuais, mas, também, à noção de corpo, de relacionamento humano, de sentimentos e de respeito.

Sexualidade é vamos dizer, o jeito de vestir, de atuar, de conversar com outras pessoas. Várias coisas estão envolvidas, diz respeito ao que somos, ao que construímos de nós mesmas, ao que representamos, sentimos, fazemos. (E9)

Para mim sexualidade é a relação no todo, é tudo o que vivemos com o marido desde o início do casamento. É como nos tratamos, o que sentimos um pelo outro, é como conseguimos falar as coisas, expressar [...] Como conseguimos falar, nos ver, ver o outro, escutar. (E4)

Eu acho que é o amor. (E7) 


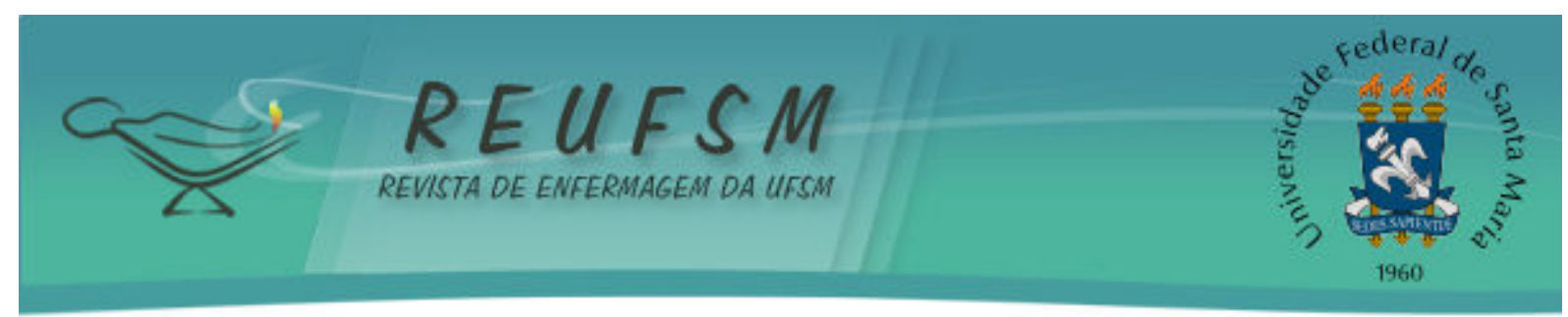

Para mim faz parte da vida, eu acho que não é tudo, mas é uma coisa muito importante, o que envolve a sexualidade para mim é o respeito. (E8)

Acho que envolve várias coisas, não pode ser só a base do sexo, o sentimento, como a gente é. (E10)

Pode-se perceber que a sexualidade foi delimitada primeiramente como ato sexual. Esses entendimentos, muitas vezes, derivam de discursos que atrelam a vivência da sexualidade a uma perspectiva genitalizante e biologicista, ainda persistentes nas discussões acerca da temática. ${ }^{17}$

Dessa forma, faz-se imprescindível compreender que sexo e sexualidade em termos de definição mostram diferenças. Assim, a palavra sexo refere-se às características biológicas que definem humanos como mulheres e homens. Já a sexualidade é um aspecto central do ser humano a qual circunda sexo, prazer, intimidade, reprodução, integrando-se no modo como nos sentimos, movemos, tocamos e somos tocados. ${ }^{18}$

Porém, embora exista essa diferença conceitual, ainda é observado que falar sobre sexualidade leva algumas mulheres a enfatizar os componentes biológicos. ${ }^{19} \mathrm{~A}$ identidade cultural que cada pessoa adquire, com o passar dos anos, delineia seu modo de visualizar e vivenciar a sexualidade. ${ }^{20}$ Como pode-se perceber em alguns relatos, a sexualidade é de conceituação ampla, e advém de uma construção cultural, a qual perpassará diversos sistemas sociais e culturais que modelarão o seu entendimento e a sua vivência. ${ }^{20}$

Muitos depoimentos estavam pautados no entendimento da sexualidade não somente sob a ótica biologicista ou ligada à genitalidade, mas a compreendendo como forma de demonstrar sentimentos e de relacionar-se com o outro. A partir desse viés, sua conceituação extrapola o exercício da genitalidade e é entendida como resultado da nossa forma de viver o mundo e de nos relacionarmos. ${ }^{19}$

Assuntos relacionados à sexualidade, até pouco tempo atrás, eram considerados tabus, limitados ao silêncio e repreendidos no ambiente familiar. Hoje, esse tema já é conduzido de maneira transparente, em algumas famílias, por meio do diálogo e da busca por apoio profissional, quando necessário. Entretanto, ainda são encontradas marcas culturais perpetuadas por meio das gerações, em especial quando se refere à sexualidade feminina. Tais marcas remetem às condutas direcionadas às mulheres, que as limitam na vivência de sua sexualidade e que tratam o sexo e o prazer como algo proibido, perigoso e até mesmo pecaminoso. ${ }^{21}$ Dessa maneira, o cuidado em saúde fica comprometido a simbologias representativas que perpetuam-se nos relacionamentos prejudicando a prevenção das DSTs/AIDS.

Diante do encontrado nos depoimentos dessa pesquisa e evidência com a literatura, a Enfermagem possui papel significativo na educação em saúde, orientando as mulheres e seus parceiros acerca das questões que perpassam a vivência sexualidade, que ainda é muito reprimida socialmente. 0 momento oportuno para tratar sobre a sexualidade é o do cuidado e a Enfermagem, por ser uma profissão que estabelece relações de cuidado com o outro, faz-se essencial. ${ }^{17}$

Acredita-se que a criação de espaços dialógicos possibilitaria as diversas formas de compreensão dessas mulheres sobre o que compreendem por sexualidade e os sentimentos atrelados à vivência desse assunto, facultando a revelação de constrangimentos, medos, angústias e inseguranças, o que pode proporcionar um cuidado de Enfermagem mais tranquilo, sensível e com qualidade. ${ }^{17}$ Além disso, esses espaços podem propiciar ao desenvolvimento da autonomia. 


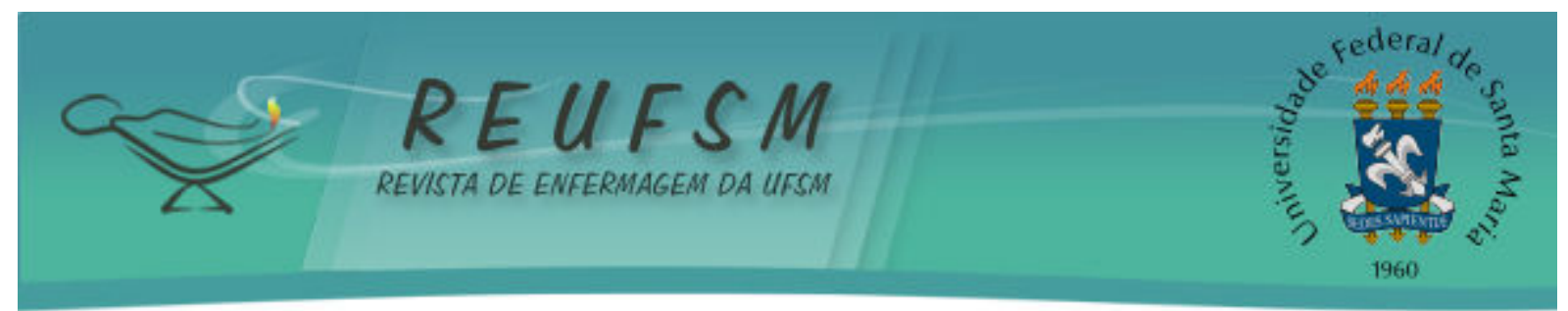

Por meio dos depoimentos foi possível identificar a percepção da sexualidade atribuída à concepção biológica, mas também se averiguou outro olhar, ligando a sexualidade à noção de corpo, relacionamento humano, entre outros. Essas percepções estão intimamente ligadas às influências social e cultural em que cada mulher convive.

Além do observado neste estudo, a cultura e as relações sociais influenciam diversos segmentos da sociedade, isso pode ser comprovado por meio de outras pesquisas, as quais apontam o quão importante é a oferta de atenção para a cultura e o meio social no qual cada um convive, pois essas exercem forte influência nos indivíduos, principalmente nas questões que envolvem a prevenção das DSTs e AIDS. ${ }^{22-23}$

Portanto, entende-se que a Enfermagem no cuidado à saúde da mulher deve procurar compreender os aspectos sociais e culturais buscando orientar as mulheres sobre sexualidade, vislumbrando que esta envolve um aspecto amplo de vivências que perpassam tanto a relação da mulher consigo mesma quanto com o outro, pormenorizando os aspectos que a relacionam estritamente à questão da genitalidade.

Desse modo, reitera-se ser necessário empreender ações relacionadas com os aspectos culturais imbricados no contexto em que as mulheres se encontram. ${ }^{24}$ Procurando torná-las agentes de transformações de suas realidades pela busca da autonomia adquirida por meio da educação em saúde de forma compartilhada.

\section{CONSIDERAÇÕES FINAIS}

Neste estudo, foi possível identificar os aspectos culturais envolvidos na construção do ser mulher, principalmente, no que diz respeito à submissão do gênero feminino ao masculino, ainda presente, embora algumas mulheres já assumam uma postura mais independente tanto em termos financeiros, quanto ao autocuidado em saúde.

No que se refere às percepções das mulheres acerca da sexualidade, foi observado que algumas a relacionam estritamente à prática sexual, enquanto outras a percebem a partir de um entendimento mais amplo, associada à noção de corporalidade, relacionamento humano e sob aspecto sentimental.

Diante disto, a Enfermagem possui papel fundamental na educação em saúde e na contribuição para o processo de empoderamento das mulheres em relação a sua saúde, já que estas demonstram uma vulnerabilidade no que diz respeito à tomada de decisão para utilização de práticas preventivas de DSTs e AIDS. Acredita-se que atitudes preventivas poderiam partir de tais mulheres, se elas obtivessem maior conhecimento em saúde sobre as questões que perpassam a vivência da sexualidade, o que, consequentemente, poderia promover maior segurança na tomada de decisão sobre a sua saúde.

Assim, este estudo suscita a necessidade de que os enfermeiros abordem, no cuidado de Enfermagem, a sexualidade das mulheres e os diversos aspectos que perpassam a sua vivência. Conhecendo seus determinantes socioculturais, estes profissionais poderão realizar abordagens de educação em saúde contextualizadas para prevenir as DSTs e a AIDS e estimular, assim, o desenvolvimento da autonomia desses sujeitos.

\section{REFERÊNCIAS}

1. Freitas GL, Vasconcelos CTM, Moura ERF, Pinheiro AKB. Discutindo a política de atenção à saúde da mulher no contexto da promoção da saúde. Rev Eletrônica Enferm [Internet]. 2009 [acesso em 2013 set 5];11(2):424-8. Disponível em: http://www.fen.ufg.br/revista/v11/n2/v11n2a26.htm.

2. Brasil. Ministério da Saúde. Secretaria de Atenção à Saúde. Departamento de Ações Programáticas Estratégicas. Política nacional de atenção integral à saúde da mulher: 


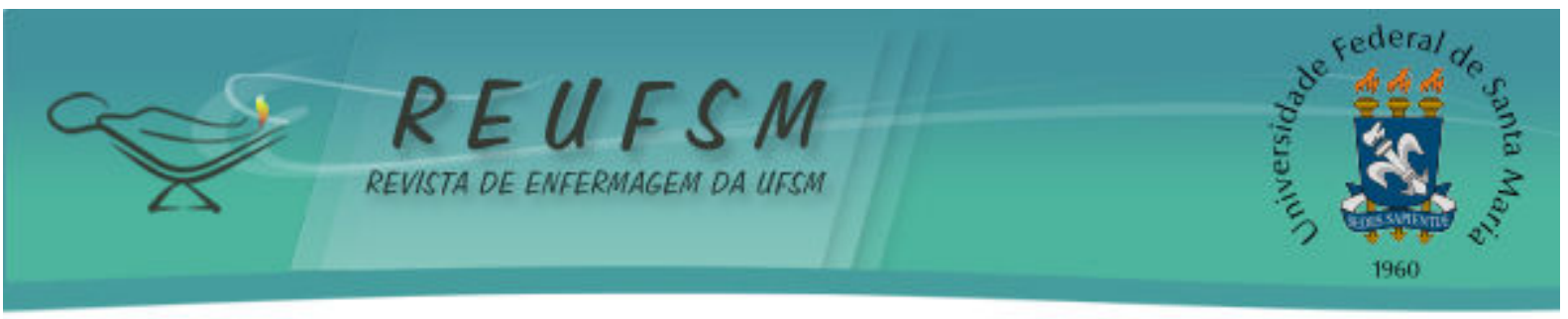

princípios e diretrizes. Brasília: Ministério da Saúde; 2009. (Série C. Projetos, Programas e Relatórios).

3. Alexander KA, Coleman CL, Deatrick JÁ, Jemott LS. Moving beyond safe sex to womencontrolled safe sex: a concept analysis. J Adv Nurs [Internet]. 2012 Aug [acesso em 2013 set 19];68(8):1858-69. Disponível em: http://www.ncbi.nlm.nih.gov/pmc/articles/PMC3290700/pdf/nihms331912.pdf.

4. UNAIDS. Report on the global AIDS epidemic 2010 [Internet]. 2010 [acesso em 2013 jun 5]. Disponível em: http://www.unaids.org/globalreport/Global_report.htm.

5. Brasil. Ministério da Saúde. Boletim Epidemiológico-AIDS e DST. 2013;ano II(1). Brasília: Ministério da Saúde; 2013. 64 p.

6. Scott JW. Gênero: uma categoria útil de análise histórica. Educação \& realidade. 1990;16(2):5-22.

7. Porto D. O significado da maternidade na construção do feminino: uma crítica bioética à desigualdade de gênero. Rev Redbioética. 2011;1(3):55-66.

8. Ribeiro KC, Silva J, Saldanha AAW. Querer é poder? A ausência do uso de preservativo nos relatos de mulheres jovens. DST, J Bras Doenças Sex Transm. 2011;23(2):84-9.

9. Garcia S, Souza FM. Vulnerabilidades ao HIV/AIDS no contexto brasileiro: iniquidades de gênero, raça e geração. Saúde Soc [Internet]. 2010 [acesso em 2013 set 19];19 Supl 2:9-20. Disponível em: http: / / www.scielo.br/scielo.php?pid=S0104-12902010000600003\&script=sci_arttext.

10. Minayo MCS. Pesquisa social: teoria, métodos e criatividade. $29^{\mathrm{a}}$ ed. Petrópolis: Vozes; 2010.

11. Brasil. Ministério da Saúde. Conselho Nacional de Saúde. Resolução CNS n 196, de 10 de outubro de 1996. Diretrizes e normas regulamentadoras de pesquisas envolvendo seres humanos. Brasília (DF): Ministério da Saúde; 1996.

12. Costa AP, Ribeiro PRM. Ser professora, ser mulher: um estudo sobre concepções de gênero e sexualidade para um grupo de alunas de pedagogia. Rev Estud Fem. 2011;19(2):475-89.

13. Faé AS, Sommacal LF, Heinzen RB, Pinheiro FKB, Trevisol FS. Planejamento familiar: escolhas contraceptivas e comportamento sexual entre alunas de uma universidade no sul do Brasil. Rev AMRIGS. 2011;55(2):147-54.

14. Oltramari LC, Camargo BV. Aids, relações conjugais e confiança: um estudo sobre representações sociais. Psicol Estud. 2010;15(2):275-83.

15. Silva $C M$, Vargens $O M C$. A percepção de mulheres quanto à vulnerabilidade feminina para contrair DST/HIV. Rev Esc Enferm USP. 2009;43(2):401-6.

16. Santos SMM, Oliveira L. Igualdade nas relações de gênero na sociedade do capital: limites, contradições e avanços. Rev Katál. 2010;13(1):11-9.

17. Sehnem GD, Ressel L, Junges CF, Silva FM, Barreto CN. A sexualidade na formação acadêmica do enfermeiro. Escola Anna Nery. 2013;17(1):90-6.

18. Morais FRC, Penna LHG, Progianti JM. A construção do conceito da sexualidade no contexto da enfermagem. Rev Pesq Cuid Fundam [Internet]. 2010 [acesso em 2013 dez 5];2(3):1071-9. Disponível em: http://www.seer.unirio.br/index.php/cuidadofundamental/article/view/538/pdf_44. 


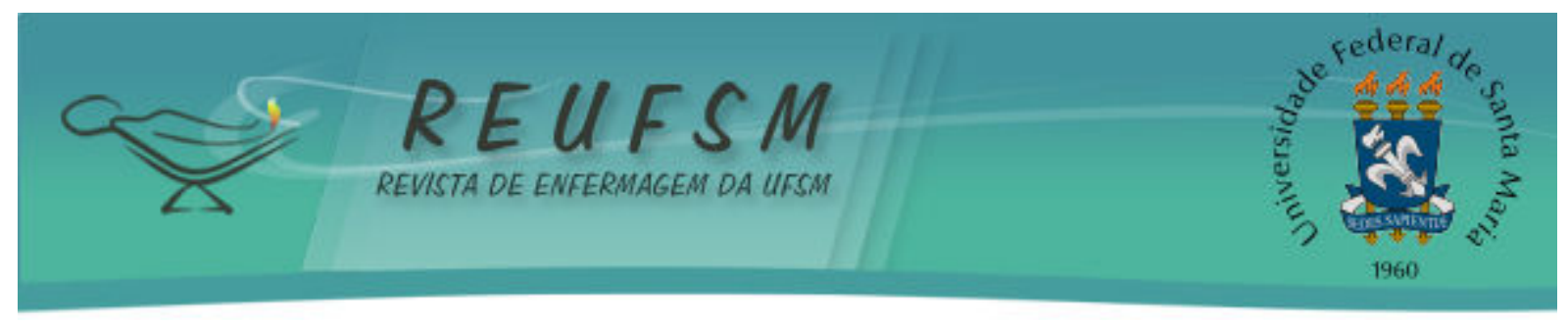

19. Sehnem GD, Ressel L, Pedro ENR, Budo MLD, Silva FM. A sexualidade no cuidado de enfermagem: retirando véus. Ciência Cuid Saúde [Internet]. 2013 [acesso em 2013 dez 8];12(1):72-9. Disponível em: http://periodicos.uem.br/ojs/index.php/CiencCuidSaude/article/view/16639/pdf1.

20. Louro GL, organizador. O corpo educado: pedagogias da sexualidade. Belo Horizonte: Autêntica; 2010.

21. Ressel LB, Junges CF, Sehnem GD, Sanfelice C. A influência da família na vivência da sexualidade de mulheres adolescentes. Escola Anna Nery Rev Enferm. 2011;15(2):245-50.

22. Sousa PRM, Sampaio Filho FJL, Ferreira AGN, Martins AKL, Gubert FA, Neves CS, et al. Aspectos culturais e sua influência na prevenção de DST/AIDS em adolescentes do grupo Emo. Adolesc Saúde. 2013;10(2):15-22.

23. Alexandre SG, Pereira MLD, Monte RS, Maia EG, Barbosa JSM, Moura SKB. Representações sociais sobre sexualidade de mulheres no contexto da AIDS. Rev RENE. 2013;14(1):120-9.

24. Wünsch S, Oliveira SG, Garcia RP, Domingues IB. Coleta de citopatológico de colo uterino: saberes e percepções de mulheres que realizam o exame. Rev Enferm UFSM [Internet]. 2011 [acesso em 2013 dez 12];1(3):360-8. Disponível em: http://cascavel.ufsm.br/revistas/ojs-2.2.2/index.php/reufsm/article/view/2543.

Data de recebimento: $19 / 12 / 2013$

Data de aceite: $24 / 10 / 2014$

Contato com autor responsável: Graciela Dutra Sehnem

Endereço postal: Rua Domingos de Almeida, 3393/Apto. 304 - Bairro São Miguel - CEP 97502-711 - Uruguaiana/RS/Brasil

E-mail: graci_dutra@yahoo.com.br 